\title{
Repeated primary care consultations for non-specific physical symptoms in children in UK: a cohort study
}

\author{
Mujahed Shraim ${ }^{1,2,3}$, Milisa Blagojevic-Bucknall ${ }^{1}$, Christian D Mallen ${ }^{1}$ and Kate M Dunn ${ }^{1 *}$
}

\begin{abstract}
Background: Non-specific physical symptoms (NSPS), such as headache and abdominal pain, are common reasons for children to consult primary care. NSPS represent a significant burden not only on society, but also on health care services, through frequent physician consultations and referrals to secondary care. Research evidence suggests a positive relationship between health and consulting behavior of parents and their children, but research on whether repeated physician consultations for NSPS in children is influenced by parental consultations for NSPS is lacking. The aim was to measure the frequency of repeated physician consultations for NSPS in children, and investigate whether this is influenced by maternal consultations for NSPS.
\end{abstract}

Methods: A cohort study of children registered with primary care practices contributing to the Consultation in Primary Care Archive database. Participants were child-mother pairs registered between January 2007 and December 2010. The cohort comprised all children $(n=1437)$ aged 2 to 16 years who consulted a physician for NSPS in 2009. Mothers' consultations for NSPS were measured between 2007 and 2008. Main outcome measures were repetition and frequency of consultations for NSPS in children (consultations for NSPS in both 2009 and 2010).

Results: Overall, 27\% of children had repeated consultations for NSPS. The three most common repeated consultations were for back pain, constipation and abdominal pain. Exposure to maternal consultation for NSPS was associated with 21\% increase in consultation frequency for NSPS (adjusted incidence rate ratio $1.21 ; 95 \% \mathrm{Cl} 1.12$, 1.31). After adjusting for child age and maternal age, maternal consultation for NSPS was associated with an increased risk of repeated consultations for NSPS in children (relative risk $1.41 ; 95 \% \mathrm{Cl} 1.16,1.73$ ). This association was also significant for specific NSPS groups including painful, gastrointestinal, and neurologic symptoms.

Conclusions: Repeated consultation for NSPS is common among children. It is important for primary care physicians and secondary care clinicians, managing children referred from primary care for NSPS, to be aware that consultation for NSPS in mothers is a risk factor for repeated consultations for NSPS among children. More research is needed to uncover exactly how parental health influences health and consulting behavior of children.

\section{Background}

Non-specific physical symptoms (NSPS) are defined as physical symptoms that lead patients to seek healthcare, and after clinical examination are not explained by clear pathological changes [1]. NSPS, such as musculoskeletal pain, abdominal pain and headache are common in children [2,3]. Annually, one third of children consult a physician for NSPS $[4,5]$. NSPS among children are associated

\footnotetext{
* Correspondence: k.m.dunn@keele.ac.uk

${ }^{1}$ Arthritis Research UK Primary Care Centre, Keele University, Keele, UK

Full list of author information is available at the end of the article
}

with functional impairment and negative impact on quality of life of children and their parents [6,7]. This represents a significant burden on healthcare services through frequent consultations, diagnostic testing, and secondary care referrals [8-10]. The causes of NSPS in children are yet to be fully explained, but are likely to be multifactorial, including genetic and psychosocial factors, including parental influence on childhood illness and health-seeking behavior [11-13]. A recent systematic review found evidence of an association between physician consultations for NSPS in parents and children, but its findings were limited by 
the methodology of empirical studies, including crosssectional designs, reliance on self-reported data, and including children from specific age groups only [14].

Population-based studies have demonstrated that NSPS persist in many children over time [15-17]. Additionally, a recent study reported an association between parental history of functional pain syndromes, such as migraine and recurrent abdominal pain, and chronic pain in their children [18]. However, evidence that this translates to physician consultations for NSPS is lacking. It is unknown whether repeated consultation for NSPS in children is influenced by parental physician consultations for NSPS. Information about the likely outcomes of children consulting physicians for NSPS is important in order to improve the quality of healthcare and patient outcomes [19].

The objective of this study was to quantify the frequency of repeated physician consultations for NSPS in children, including different patterns of NSPS, and investigate whether frequency and repetition of consultation for NSPS in children are influenced by maternal consultations for NSPS.

\section{Methods}

\section{Study design and setting}

This was a cohort study of children registered with primary care practices. We used the Consultation in Primary Care Archive (CiPCA), a primary care research database containing consultations occurring at 12 practices in North Staffordshire, UK. The total population registered mid-year 2009 was 104,911. CiPCA is a high-quality, anonymized and validated database, the contributing practices have regular cycles of training, assessment and feedback with respect to the quality of coded clinical data [20]. Data from CiPCA on the annual consultation prevalence for musculoskeletal conditions are comparable to data from larger national primary care databases [21].

Ethical approval for the CiPCA database was given by the North Staffordshire and Staffordshire Research Ethics Committees (UK), who gave permission to download and store anonymized medical record information for research use from participating general practices. All general practices participating in CiPCA inform their patient populations that their anonymized records will be used in this way and all patients are offered the opportunity to withdraw their records from inclusion in CiPCA.

\section{Participants}

Eligible participants were children and mothers registered with CiPCA practices between January 2007 and December 2010. The cohort consisted of all children aged 2 to 16 years in 2009 who consulted a physician for NSPS in 2009. One child per household was randomly selected because the main exposure of interest was maternal physician consultation for NSPS, which would be the same for siblings, thus avoiding over representing families with more than one child. About $99.3 \%$ of babies born in England and Wales in 2010 have a mother aged 17 to 45 years at the birth of the child [22]. Therefore, a mother was defined as a female aged between 17 and 45 years at the birth of the child and bearing the same household identification code (to identify all persons living in a household and registered with the same practice). We excluded households with more than one female meeting our definition of a mother to minimize the potential for classifying sisters or grandmothers as mothers of selected children.

\section{Outcome measures}

The primary outcome measure was repetition of consultation for NSPS in children, dichotomized as: (a) children with repeated consultations for NSPS, consisting of children who consulted for NSPS in 2009 and at least once in 2010; (b) children without repeated consultations for NSPS, consisting of children who consulted for NSPS in 2009 but not in 2010. We also measured the frequency of consultation for NSPS among children in 2009 and 2010.

NSPS consultations were defined using a comprehensive list of standardized diagnostic Read codes for physical symptoms (presented in Table 1). Read codes are a hierarchy of morbidity, symptoms and process codes that are used to record all electronic morbidity data in UK primary care [23]. The full list of Read codes for physical symptoms is available from the authors.

NSPS are usually recorded and coded in the physician's computer system as symptom diagnoses when a precise diagnosis is unavailable. We classified consultations as NSPS if physical symptoms diagnoses were coded as the main reason for encounter, and the free-text records suggested that the cause was not-specific (e.g. a girl consulting with headache without objective pathological changes on physical examination and/or diagnostic testing). We excluded consultations for physical symptoms due to trauma or injury. We also excluded consultations for included physical symptoms in pregnant mothers at the time of consultations.

We examined the repetition of consultation for NSPS in children by type of NSPS (painful and not-painful symptoms) and by three body systems (musculoskeletal (e.g. joint pain), gastrointestinal (e.g. abdominal pain), and neurological symptoms (e.g. headache)); see Table 1.

\section{Ascertainment of maternal consultations for NSPS}

All consultations made by mothers between 1 January 2007 and 31 December 2008 were extracted. Consultations for NSPS in mothers were identified and classified into groups using the same method described for children. The child exposure to maternal consultation for NSPS was 
Table 1 List of non-specific physical symptoms

\begin{tabular}{|c|c|}
\hline \multicolumn{2}{|c|}{ Non-specific physical symptoms according to bodily system } \\
\hline Musculoskeletal symptoms & $\begin{array}{l}\text { Burning sensation in sexual organs } \\
\text { or rectum }\end{array}$ \\
\hline Pain in extremities & Dysmenorrhea (painful menstruation) \\
\hline Back pain & $\begin{array}{l}\text { Metrorrhagia (irregular menstrual } \\
\text { periods) }\end{array}$ \\
\hline Joint pain & $\begin{array}{l}\text { Menorrhagia (heavy menstrual } \\
\text { bleeding) }\end{array}$ \\
\hline Muscles soreness & Sexual indifference (decreased libido)* \\
\hline Gastrointestinal symptoms & Dyspareunia (pain during intercourse) \\
\hline Vomiting & Neurologic symptoms \\
\hline Abdominal pain & Dizziness \\
\hline Nausea & $\begin{array}{l}\text { Fainting (syncope) or loss of } \\
\text { consciousness }\end{array}$ \\
\hline Abdominal bloating & Transient Amnesia (loss of memory) \\
\hline Diarrhea & Transient Aphonia (loss of voice) \\
\hline Constipation & Transient Diplopia (double vision) \\
\hline Multiple food intolerance & Transient blurred vision \\
\hline Globus (lump in the throat) & Transient blindness \\
\hline $\begin{array}{l}\text { Dysphagia (difficulty } \\
\text { swallowing) }\end{array}$ & Transient seizure or convulsion \\
\hline Cardiopulmonary symptoms & Transient Ataxia (trouble walking) \\
\hline Palpitations & Transient Paresis (paralysis) \\
\hline Chest pain & $\begin{array}{l}\text { Paresthesia (numbness or tingling } \\
\text { sensation) }\end{array}$ \\
\hline Hyperventilation or Dyspnea & Headache \\
\hline Hot or cold spells (sweat) & Weakness in parts of the body \\
\hline Urogenital symptoms & Heavy feelings in arms or legs \\
\hline Pain during urination & General symptoms \\
\hline Difficulty urinating (Dysuria) & Fatigue \\
\hline
\end{tabular}

*Symptoms were excluded from analysis for children.

defined as exposure to at least one maternal consultation for NSPS between 1 January 2007 and 31 December 2008.

\section{Measurement of other variables}

We extracted data on sociodemographic and health related characteristics for children and mothers from the CiPCA database. Sociodemographic variables included child sex and age, child birth order, household members' count, number of siblings in household, index of multiple deprivation (IMD) 2007 scores for residential area level deprivation, and maternal age. Health related variables included primary care practice and maternal history of anxiety or depressive disorders.

Children's age was split into tertiles (2-6, 7-11 and 12-16 years), and maternal age into quartiles (19-28, 29-39, 40-50 and 51-61 years). Maternal age in 2009 was used to reflect their age at the time of children's consultation.

The household identification codes were used to identify all household members of included children. Younger siblings for index children were defined as persons from the same household born after the index child, whereas older siblings were defined as persons from the same household and aged 16 or less at the birth of the index child. The birth order of the child was classified as "first" if the child had no siblings or if the child was the oldest child in the household (with no other household members' meeting the definition for a sibling). Households with 13 or more members were excluded to prevent including families living in shared households.

The IMD 2007 scores were constructed by the Department of Communities and Local Government, and conceptualized as a weighted area level aggregation of scores for seven domains of deprivation including income; employment; health deprivation and disability; education, skills and training; barriers to housing and services; crime; living environment [24]. IMD 2007 scores range from $0 \%$ to $100 \%$ where higher scores indicate greater deprivation [24]. The IMD 2007 scores for children's residential area level deprivation were presented as quintiles with ' 1 ' representing the most affluent and ' 5 ' presenting the most deprived.

Maternal history of anxiety/depressive disorders was identified by searching mothers' records between 2007 and 2008 using a list of pre-defined anxiety/depression Read codes (available on request from the authors).

\section{Statistical analysis}

Chi-squared tests and Mann-Whitney $U$ tests were performed to test for significant baseline differences between exposed and unexposed children to maternal NSPS consultation. The Cox proportional hazards regression with invariant time was used to obtain estimates of relative risk $(\mathrm{RR})$ and associated 95\% confidence intervals (CI) as a summary measure of association between predictors and repetition of consultation for NSPS in children. Univariable analyses were initially performed to obtain individual associations between each predictor and repeated consultation for NSPS. All significant predictors $(\mathrm{p}<0.05)$ were subsequently included in the multivariable analysis. These analyses were re-performed considering repeated consultation in children for the same type of NSPS that the mother had previously consulted for. Poisson regression with robust variance estimator was used to estimate incidence rate ratios (IRR) with $95 \% \mathrm{CI}$ for the association between exposure to maternal consultations for NSPS and consultation frequency for NSPS in children.

All analyses were performed using IBM SPSS Statistics (version 20.0) [25] and STATA (version 12) [26].

\section{Results}

\section{Characteristics of children}

We included 1437 child-mother pairs. Differences in the baseline characteristics of children exposed and unexposed 
to maternal consultations for NSPS are presented in Table 2. There were no statistically significant differences between children's baseline characteristics except for child birth order and maternal history of anxiety/depression disorders. More children exposed to maternal consultations for NSPS were "not first" in birth order (44\%) than unexposed children (39\%, $p=0.029)$. $37 \%$ of exposed and $14 \%$ of unexposed children had a history of maternal anxiety/depression disorders $(p<0.001)$.

\section{Proportions of children with repeated and frequent consultations for NSPS}

$27 \%$ of the children had repeated consultations for any NSPS. $25 \%$ and $17 \%$ of all children had repeated consultations for painful and not-painful NSPS, respectively. Repeated consultations for gastrointestinal, musculoskeletal, and neurological symptoms occurred in $15 \%, 13 \%$, and $10 \%$ of children, respectively. The three most common repeated Consultations for NSPS were for back pain (18\%), constipation (17\%), and abdominal pain (15\%); (Figure 1). Consultation frequency for NSPS in children in the two-year period ranged between 1 and 16 consultations $($ median $=1)$.

The associations between maternal consultation for NSPS and repeated NSPS consultations in children

$57 \%$ of children with repeated consultations for NSPS and $46 \%$ of children without repeated consultations for NSPS were exposed to maternal NSPS consultations. Univariable analysis found consultation for any NSPS in mothers was significantly associated with an increased risk of repeated consultation for any NSPS in children (RR 1.41, 95\% CI 1.15 to 1.72). This finding remained following adjustment for predictors deemed significant

Table 2 Baseline characteristics of children according to exposure to maternal consultations for NSPS

\begin{tabular}{|c|c|c|c|}
\hline Variable & $\begin{array}{l}\text { Exposed to maternal visits } \\
\text { for NSPS }(n=703) n(\%)\end{array}$ & $\begin{array}{l}\text { Unexposed to maternal visits } \\
\text { for NSPS }(n=734) n(\%)\end{array}$ & $p$-value \\
\hline \multicolumn{4}{|l|}{ Child age group } \\
\hline $2-6$ years & $229(32.6)$ & $254(34.6)$ & \multirow[t]{3}{*}{0.069} \\
\hline $7-11$ years & $188(26.7)$ & $158(21.5)$ & \\
\hline $12-16$ years & $286(40.7)$ & $322(43.9)$ & \\
\hline \multicolumn{4}{|l|}{ Child gender } \\
\hline Female & $392(55.8)$ & $398(54.2)$ & \multirow[t]{2}{*}{0.594} \\
\hline Male & $311(44.2)$ & $336(45.8)$ & \\
\hline \multicolumn{4}{|l|}{ Mother age group } \\
\hline $19-28$ & $94(13.4)$ & $113(15.4)$ & \multirow[t]{4}{*}{0.470} \\
\hline 29-39 & $305(43.4)$ & $301(41.0)$ & \\
\hline $40-50$ & $269(38.3)$ & 291 (39.6) & \\
\hline $51-61$ & $35(5.0)$ & $29(4.0)$ & \\
\hline \multicolumn{4}{|l|}{ Child birth order } \\
\hline First & $391(55.6)$ & $451(61.4)$ & \multirow[t]{2}{*}{0.029} \\
\hline Not first & $312(44.4)$ & $283(38.6)$ & \\
\hline Household members' count ${ }^{\mathrm{a}}$ & $4(1)$ & $3(1)$ & 0.093 \\
\hline Number of siblings ${ }^{a}$ & $1(1)$ & $1(1)$ & 0.254 \\
\hline \multicolumn{4}{|l|}{ IMD 2007quintiles ${ }^{\text {b }}$} \\
\hline 1 & $139(19.8)$ & $167(22.8)$ & \multirow[t]{5}{*}{0.161} \\
\hline$\|$ & $136(19.3)$ & 144 (19.6) & \\
\hline III & $143(20.3)$ & $154(21.0)$ & \\
\hline IV & $166(23.6)$ & $135(18.4)$ & \\
\hline V & $115(16.4)$ & $129(17.6)$ & \\
\hline \multicolumn{4}{|c|}{ Maternal history of anxiety or depression } \\
\hline No & $441(62.7)$ & $635(86.5)$ & \multirow[t]{2}{*}{$<0.001$} \\
\hline Yes & $262(37.3)$ & 99 (13.5) & \\
\hline
\end{tabular}

NSPS - non-specific physical symptoms; ${ }^{a}$ Numbers are Median (Interquartile range); IMD - Index of multiple deprivation; ${ }^{\mathrm{b}}$ IMD 2007 scores were missing for 4 of exposed $(0.5 \%)$ and 5 of unexposed $(0.7 \%)$ children. Differences between exposed and unexposed children were tested using Mann-Whitney $\mathrm{U}$ test for household members' count and number of siblings, and Chi-squared tests for the remaining variables. 


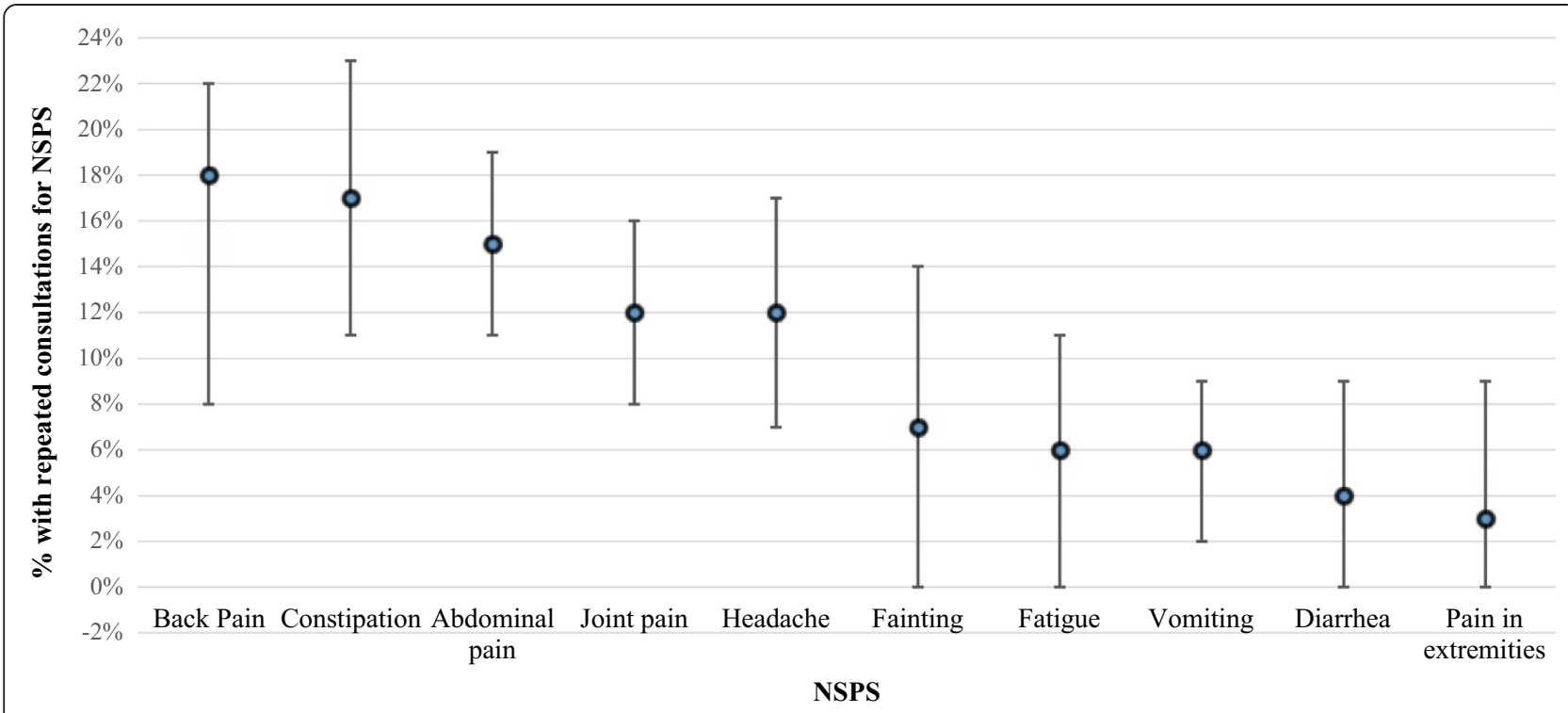

Figure 1 Percentage of children with repeated consultations for NSPS. Bars represent percentages with 95\% Cl; NSPS - non-specific physical symptoms.

$(\mathrm{p}<0.05)$ in univariable analyses (adjusted RR 1.41, 95\% CI 1.16 to 1.73); (Table 3).

In addition to maternal consultation for any NSPS, child age was the only statistically significant predictor of repeated consultations for any NSPS; those aged 7-11 and 12-16 years had a one and a half times and almost two times the risk of repeated consultation compared to the youngest age group ( $R R=1.48,95 \%$ CI 1.09, 2.01 and $1.89,95 \%$ CI 1.39, 2.57 respectively).

With regards to repeated consultations for more specific types of NSPS, we found significant associations between maternal consultations for painful, gastrointestinal, and neurologic NSPS and repeated consultations for the same type of NSPS in children after adjustment for other significant predictors (child age, maternal age, and maternal history for anxiety/depression; Table 4). Children exposed to maternal consultations for painful NSPS were at 53\% increased risk of consulting for painful NSPS as compared to non-exposed children (adjusted RR 1.53, 95\% CI 1.18, 1.97).

The associations between maternal consultation for NSPS and frequency of consultation for NSPS in children

The median number of consultation for NSPS in the two-year period was 2 (range 1-12) consultations for exposed children and 1 consultation (range 1-16) for unexposed children. Figure 2 shows the number of NSPS consultations in children by exposure status to maternal consultation for NSPS. Maternal consultation for NSPS was associated with a $22 \%$ increase in the incidence rate of consultation for NSPS in children (unadjusted IRR 1.22; 95\% CI 1.13, 1.31). This association remained significant (IRR 1.21; 95\% CI 1.12, 1.31) after adjusting for other significant predictors (child age group, maternal age group, and maternal history of anxiety/depression).

\section{Discussion}

This study found that over a quarter (27\%) of children had repeated consultations for NSPS. The most common repeated consultations for NSPS in children were for back pain, constipation, and abdominal pain. We found significant associations between consultations for different types of NSPS in mothers and repetition of similar consultations in their children. These associations were clearest for any NSPS, painful, gastrointestinal, and neurological symptoms. We also found that exposure to maternal consultation for NSPS was associated with increase in consultation frequency for NSPS among children.

\section{Comparison with other studies}

Our findings are similar to those reported in previous studies. A systematic review examining the recurrence/ persistence of abdominal pain among children reported that $29 \%$ of children with baseline abdominal pain had recurrent/persistent abdominal pain using various followup periods, ranging between 1-5year periods [27]. Previous studies also reported that children of parents with irritable bowel syndrome (IBS) have more physician consultations for NSPS than children of parents without IBS $[28,29]$. This is the first cohort study to examine repeated physician consultations for NSPS in children, in relation to maternal physician consultations for NSPS. Prior research, using self-reported data, provides indirect evidence to support the findings of the current study. One study found that NSPS among adults aged 36 years were 
Table 3 Risk factors for repeated consultations for NSPS in children

\begin{tabular}{|c|c|c|c|c|c|c|}
\hline & $\begin{array}{l}\text { Children with repeated } \\
\text { consultations for NSPS } \\
(n=390)\end{array}$ & $\begin{array}{l}\text { Children without repeated } \\
\text { consultations for NSPS } \\
(n=1047)\end{array}$ & $\begin{array}{l}\text { Crude RR } \\
(95 \% \text { Cls })\end{array}$ & $P$-value & $\begin{array}{l}\text { Adjusted }^{a} \text { RR } \\
(95 \% \text { Cls })\end{array}$ & $P$-value \\
\hline \multicolumn{7}{|l|}{ Maternal visits for any NSPS } \\
\hline No & 166 & 568 & 1 & & 1 & \\
\hline Yes & 224 & 479 & $1.41(1.15,1.72)$ & 0.001 & $1.41(1.16,1.73)$ & 0.001 \\
\hline \multicolumn{7}{|l|}{ Child gender } \\
\hline Male & 163 & 484 & 1 & & & \\
\hline Female & 227 & 563 & $1.14(0.93,1.40)$ & 0.200 & - & - \\
\hline \multicolumn{7}{|l|}{ Child age group } \\
\hline $2-6$ years & 90 & 393 & 1 & & 1 & \\
\hline $7-11$ years & 94 & 252 & $1.46(1.09,1.95)$ & 0.011 & $1.48(1.09,2.01)$ & 0.012 \\
\hline $12-16$ years & 206 & 402 & $1.82(1.42,2.33)$ & $<0.001$ & $1.89(1.39,2.57)$ & $<0.001$ \\
\hline \multicolumn{7}{|l|}{ Child birth order } \\
\hline Not first & 160 & 435 & 1 & & & \\
\hline First & 230 & 612 & $1.02(0.83,1.24)$ & 0.879 & - & - \\
\hline Household Members' count ${ }^{b}$ & $4(1)$ & $4(1)$ & $0.95(0.88,1.03)$ & 0.254 & - & - \\
\hline Number of siblings ${ }^{b}$ & $1(1)$ & $1(1)$ & $1.00(0.90,1.11)$ & 0.945 & - & - \\
\hline \multicolumn{7}{|l|}{ IMD 2007 quintiles } \\
\hline । & 75 & 231 & 1 & & & \\
\hline$\|$ & 70 & 210 & $1.02(0.74,1.41)$ & 0.905 & - & - \\
\hline III & 84 & 213 & $1.15(0.85,1.58)$ & 0.367 & - & - \\
\hline IV & 94 & 207 & $1.27(0.94,1.73)$ & 0.118 & - & - \\
\hline V & 65 & 179 & $1.09(0.78,1.52)$ & 0.623 & - & - \\
\hline \multicolumn{7}{|l|}{ Maternal age group } \\
\hline $19-28$ years & 47 & 160 & 1 & & 1 & \\
\hline 29-39 years & 148 & 458 & $1.08(0.78,1.49)$ & 0.663 & $0.83(0.58,1.18)$ & 0.298 \\
\hline $40-50$ years & 170 & 390 & $1.34(0.97,1.85)$ & 0.078 & $0.85(0.58,1.25)$ & 0.414 \\
\hline 51-61years & 25 & 39 & $1.72(1.06,2.80)$ & 0.028 & $0.97(0.57,1.69)$ & 0.933 \\
\hline \multicolumn{7}{|l|}{$\begin{array}{l}\text { Maternal history of anxiety } \\
\text { or depression }\end{array}$} \\
\hline No & 276 & 800 & 1 & & & \\
\hline Yes & 114 & 247 & $1.23(0.99,1.53)$ & 0.062 & - & - \\
\hline
\end{tabular}

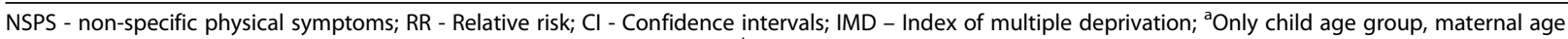
group, and maternal visits for any NSPS were retained in the final model; ${ }^{b}$ Numbers are Median (Interquartile range).

significantly associated with abdominal pain and poor parental health when participants were aged 15 years [30]. In the same study, headache in childhood was linked to headache (odds ratio (OR) 2.22, 95\% CI 1.62 to 3.06) and multiple NSPS (OR 2.22, 95\% CI 1.62 to 3.06 ) in adulthood.

\section{Interpretation}

The exact mechanisms underlying the associations between maternal consultation for NSPS and repetition of similar and frequent consultations in children are still to be determined. Research evidence from primary care and population-based studies suggest that genetic, social and environmental factors may be involved. There is some evidence that genetic effects contribute to the onset of some NSPS, including headache and IBS [31-33]. However, it seems unlikely that genetic factors are able to fully explain this because the observed associations were only significant for painful NSPS, and repeated consultations for NSPS increased with increasing child's age. Research suggests that exposure of family members to certain social and environmental factors (e.g. socioeconomic circumstances and poor family functioning) is associated with greater reporting of NSPS [34,35]. Another plausible explanation for our findings is childhood social learning of illness behavior (such as family definition of illness, recognition and perceived seriousness of symptoms, and 
Table 4 Risk for repeated consultations for specific NSPS in children, by history of maternal consultation for the same specific NSPS

\begin{tabular}{|c|c|c|c|c|}
\hline $\begin{array}{l}\text { Children with repeated } \\
\text { consultations for the } \\
\text { same type of NSPS in } \\
\text { their }\end{array}$ & $\begin{array}{l}\text { Children without repeated } \\
\text { consultations for the same } \\
\text { type of NSPS in their mothers }\end{array}$ & $\begin{array}{l}\text { Crude RR } \\
\text { (95\% Cls) }\end{array}$ & $P$-value & $\begin{array}{l}\text { Adjusted RR } \\
\text { (95\% Cls) }\end{array}$ \\
\hline
\end{tabular}

\section{Maternal visits for painful NSPS}

No

Yes

\section{6}

124

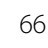

23

81

29

Yes

Maternal visits for neurological NSPS

No

$23 \quad 175$

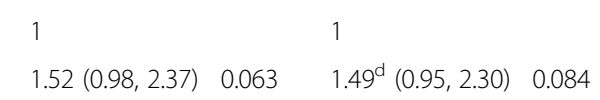
$1.72(1.12,2.62) \quad 0.013 \quad 1.72^{c}(1.12,2.62) \quad 0.013$
Yes 11
34
1

$2.10(1.03,4.32) \quad 0.042$
1

$2.10^{\mathrm{e}}(1.03,4.32) \quad 0.042$

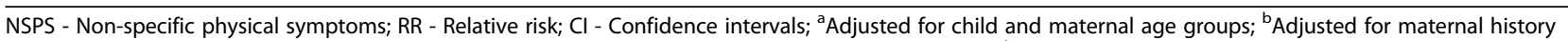
for anxiety/depression; ${ }^{C}$ Only maternal visits for gastrointestinal NSPS was retained in the final model; ${ }^{d}$ Adjusted for child age group; ${ }^{e}$ Only maternal visits for neurological NSPS was retained in the final model.

reaction to symptoms), which has been hypothesized to play an important role in the development of illness and healthseeking behavior in children $[4,36]$. A number of studies have suggested that parental responses and attitudes toward the child's illness (reinforcement) and parental coping mechanisms with their own illness (role modelling) may influence symptoms frequency, disability days, and healthcare consultations in their children when they become adults $[37,38]$. For example, women with IBS were more likely than women without IBS to emulate illness

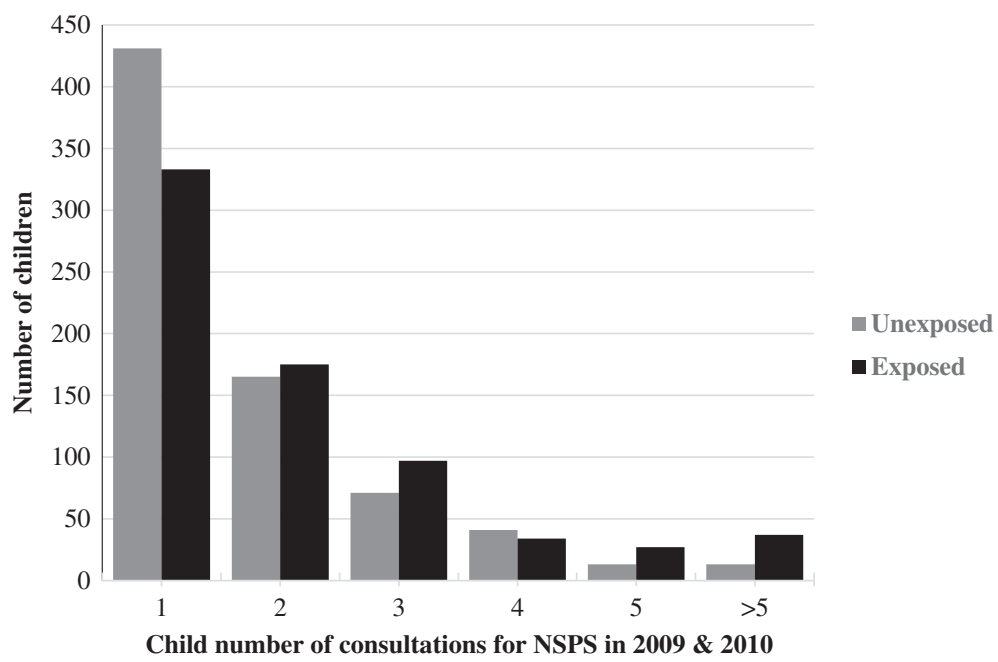

Figure 2 Number of child's NSPS consultations by exposure status to maternal consultation for NSPS. 
behavior of their parents and to recall that their parents reinforced their illness behavior by rewarding them with special privileges [37].

\section{Strengths and limitations}

This study is strengthened by using documented physician consultations and prospective data collection. The child's exposure to maternal consultations was measured using electronic medical records, which is considered a more reliable source of data than recall [39]. Another important strength is that the exposure to maternal consultations for NSPS was ascertained before studying the repetition of consultations for NSPS in children, which provides a clear temporal relationship. Additionally, the CiPCA database has been shown to be a high quality dataset [20].

This study also has some limitations which should be considered. We could not assemble an inception cohort of children presenting for the first time with NSPS, because we have no information on time of onset of these symptoms. Additionally, selecting those with new episodes of healthcare consultation does not necessarily define the onset of the symptoms, and is therefore of limited value [40]. However, this cohort included a group of consecutive children presenting with NSPS, which was clearly defined and assembled at the time of the child consultation for NSPS. Another potential limitation is diagnostic misclassification, which is a common problem in primary care [41]. However, diagnostic misclassification is unlikely to completely explain our findings due to the high quality of coded clinical data within CiPCA practices. For example, $97 \%$ of all physician consultations that occurred in the CiPCA practices in 2006 were given a morbidity code [42]. Additionally, the current classification system used in primary care allows for coding definitive diagnoses (e.g. urinary tract infection) as well as symptom diagnoses (e.g. abdominal pain) when a definitive diagnosis is not established, which reduces the potential for diagnostic misclassification. Another limitation is that because we excluded NSPS consultations in pregnant mothers, children whose mothers were pregnant during the study period may have been less likely to be exposed, especially if younger children were more likely to have mothers who were pregnant. However, this is unlikely to have resulted in systematic bias because the proportions of exposed and unexposed children were comparable in each age group. Additionally, we did not examine whether other alternative diagnoses of well-defined conditions were made for NSPS among children at a later stage because consultation data since 2010 was not available to us when we conducted the study.

\section{Generalizability}

In the UK over $97 \%$ of the population is registered with a primary care practice, which usually provides first point access to non-emergency healthcare [43]. This cohort consisted of all children that could be paired with a mother from 12 primary care practices, reducing the chance of selection bias. We also assembled a clearly defined cohort of consecutive consulters for NSPS at the time of their consultation. This enhances the internal and external validity of this study, and therefore these findings are highly likely to be generalizable.

\section{Implications for clinical practice and future research}

This study has provided new prospective evidence that repeated and frequent consultations for NSPS among children are influenced by consultations for NSPS in their mothers. These findings suggest that the potential for repeated and frequent consultations for NSPS in children should be viewed with context of the family. More research is required to fully explain the exact mechanisms underlying the associations between exposure to maternal consultations for NSPS and the frequency and repeated consultations for NSPS in the child. Such research may shed light on effective management strategies to reduce the frequency and the number of consultations for NSPS in children.

\section{Conclusions}

This study showed that considerable proportions of children have repeated physician consultations for NSPS, and that repeated and frequent consultations for NSPS are influenced by previous exposure to maternal consultations for NSPS. Medical practitioners managing children presenting with NSPS in both primary and secondary care should be aware of these links. More research with longer follow-up periods is needed to fully explain the influence of parental health on the health and consulting behavior of children.

\section{Competing interests}

The authors declare that they have no competing interests.

\section{Authors' contributions}

MS and KMD devised the study. MS analyzed the data and wrote the first draft of the manuscript. MS, MB, CDM, and KMD read and contributed to subsequent versions, and approved the final manuscript.

\section{Acknowledgements}

We would like to thank the Keele GP Research Partnership and the Informatics team at the Arthritis Research UK Primary Care Centre. MS is funded by NHS Research and Development Support for New Medical Schools. CDM is funded by a Clinician Scientist Fellowship (19634) from Arthritis Research UK. KMD is funded through a Research Career Development Fellowship from the Wellcome Trust [083572]. MB is supported by a NIHR National School for Primary Care Research Fellowship. CiPCA is funded by the North Staffordshire Primary Care Research Consortium and Keele University Institute for Primary Care and Health.

The funders had no role in study design, data collection and analysis, decision to publish, or preparation of the manuscript.

\section{Author details}

${ }^{1}$ Arthritis Research UK Primary Care Centre, Keele University, Keele, UK. ${ }^{2}$ Work Environment Department, University of Massachusetts Lowell, Lowell, 
Massachusetts, USA. ${ }^{3}$ Center for Disability Research, Liberty Mutual Research Institute for Safety, Hopkinton, Massachusetts, USA.

Received: 4 September 2014 Accepted: 12 November 2014 Published online: 05 December 2014

\section{References}

1. Kroenke K: Studying symptoms: sampling and measurement issues. Ann Intern Med 2001, 134(9 Pt 2):844-853.

2. Roth-Isigkeit A, Thyen U, Raspe HH, Stoven H, Schmucker P: Reports of pain among German children and adolescents: an epidemiological study. Acta Paediatr 2004, 93(2):258-263.

3. Perquin CW, Hazebroek-Kampschreur AA, Hunfeld JA, Bohnen AM, van Suijlekom-Smit LW, Passchier J, van der Wouden JC: Pain in children and adolescents: a common experience. Pain 2000, 87(1):51-58.

4. Cardol M, van den Bosch WJ, Spreeuwenberg P, Groenewegen PP, van Dijk L, de Bakker DH: All in the family: headaches and abdominal pain as indicators for consultation patterns in families. Ann Fam Med 2006, 4(6):506-511.

5. van Eekelen FC, Perquin CW, Hunfeld JA, Hazebroek-Kampschreur AA, van Suijlekom-Smit LW, Koes BW, Passchier J, van der Wouden JC Comparison between children and adolescents with and without chronic benign pain: consultation rate and pain characteristics. $\mathrm{Br} J \mathrm{Gen}$ Pract 2002, 52(476):211-213.

6. Gold Jl, Mahrer NE, Yee J, Palermo TM: Pain, fatigue, and health-related quality of life in children and adolescents with chronic pain. Clin J Pain 2009, 25(5):407-412.

7. Hunfeld JA, Perquin CW, Hazebroek-Kampschreur AA, Passchier J, van Suijlekom-Smit LW, van der Wouden JC: Physically unexplained chronic pain and its impact on children and their families: the mother's perception Psychol Psychother 2002, 75(Pt 3):251-260.

8. Jackson JL, Kroenke K: Prevalence, impact, and prognosis of multisomatoform disorder in primary care: a 5-year follow-up study. Psychosom Med 2008, 70(4):430-434.

9. Little P, Somerville J, Williamson I, Warner G, Moore M, Wiles R, George S, Smith A, Peveler R: Family influences in a cross-sectional survey of higher child attendance. Br J Gen Pract 2001, 51(473):977-981. 984.

10. Reid S, Wessely S, Crayford T, Hotopf M: Medically unexplained symptoms in frequent attenders of secondary health care: retrospective cohort study. BMJ 2001, 322(7289):767.

11. El-Metwally A, Mikkelsson M, Stahl M, Macfarlane GJ, Jones GT, Pulkkinen L, Rose RJ, Kaprio J: Genetic and environmental influences on non-specific low back pain in children: a twin study. Eur Spine J 2008, 17(4):502-508

12. Levy RL, Whitehead WE, Von Korff MR, Feld AD: Intergenerational transmission of gastrointestinal illness behavior. Am J Gastroenterol 2000, 95(2):451-456.

13. Kroner-Herwig B, Gassmann J, van Gessel H, Vath N: Multiple pains in children and adolescents: a risk factor analysis in a longitudinal study. J Pediatr Psychol 2011, 36(4):420-432.

14. Shraim M, Mallen CD, Dunn KM: GP consultations for medically unexplained physical symptoms in parents and their children: a systematic review. Br J Gen Pract 2013, 63(610):e318-e325.

15. Mikkelsson M, El-Metwally A, Kautiainen H, Auvinen A, Macfarlane GJ, Salminen JJ: Onset, prognosis and risk factors for widespread pain in schoolchildren: a prospective 4-year follow-up study. Pain 2008, 138(3):681-687.

16. El-Metwally A, Salminen JJ, Auvinen A, Kautiainen H, Mikkelsson M: Prognosis of non-specific musculoskeletal pain in preadolescents: a prospective 4-year follow-up study till adolescence. Pain 2004, 110(3):550-559.

17. Perquin CW, Hunfeld JA, Hazebroek-Kampschreur AA, van Suijlekom-Smit LW, Passchier J, Koes BW, van der Wouden JC: The natural course of chronic benign pain in childhood and adolescence: a two-year population-based follow-up study. Eur J Pain 2003, 7(6):551-559

18. Coenders A, Chapman C, Hannaford P, Jaaniste T, Qiu W, Anderson D, Glogauer M, Goodison-Farnsworth E, McCormick M, Champion D: In search of risk factors for chronic pain in adolescents: a case-control study of childhood and parental associations. J Pain Res 2014, 7:175-183.

19. Hemingway $H$, Croft P, Perel P. Hayden JA, Abrams K Timmis A, Briggs A, Udumyan R, Moons KG, Steyerberg EW, Roberts I, Schroter S, Altman DG, Riley RD, PROGRESS Group: Prognosis research strategy (PROGRESS) 1: a framework for researching clinical outcomes. BMJ 2013, 346:e5595.

20. Porcheret M, Hughes R, Evans D, Jordan K, Whitehurst T, Ogden H, Croft P, North Staffordshire General Practice Research Network: Data quality of general practice electronic health records: the impact of a program of assessments, feedback, and training. J Am Med Inform Assoc 2004, 11(1):78-86.

21. Jordan KP, Kadam UT, Hayward R, Porcheret M, Young C, Croft P: Annual consultation prevalence of regional musculoskeletal problems in primary care: an observational study. BMC Musculoskelet Disord 2010 11:144-2474-11-144.

22. Office for National Statistics: Live births in England and Wales by characteristics of mother 2010. 2011 [http://www.ons.gov.uk/ons/ publications/re-reference-tables.html?edition=tcm\%3A77-230704]

23. Chisholm J: The Read clinical classification. BMJ 1990, 300(6732):1092.

24. Department for Communities and Local Government: The English Indices of Deprivation 2007. London: Department for Communities and Local Government: 2007.

25. IBM Corp: IBM SPSS Statistics for Windows. 2011. 20.0

26. StataCorp: Stata Statistical Software. 2011:12.

27. Gieteling MJ, Bierma-Zeinstra SM, Passchier J, Berger MY: Prognosis of chronic or recurrent abdominal pain in children. $J$ Pediatr Gastroenterol Nutr 2008, 47(3):316-326.

28. Levy RL, Langer SL, Walker LS, Romano JM, Christie DL, Youssef N, DuPen MM Feld AD, Ballard SA, Welsh EM, Jeffery RW, Young M, Coffey MJ, Whitehead WE: Cognitive-behavioral therapy for children with functional abdominal pain and their parents decreases pain and other symptoms. Am J Gastroenterol 2010, 105(4):946-956

29. Levy RL, Whitehead WE, Walker LS, Von Korff M, Feld AD, Garner M, Christie D: Increased somatic complaints and health-care utilization in children: effects of parent IBS status and parent response to gastrointestinal symptoms. Am J Gastroenterol 2004, 99(12):2442-2451.

30. Hotopf M, Mayou R, Wadsworth M, Wessely S: Childhood risk factors for adults with medically unexplained symptoms: results from a national birth cohort study. Am J Psychiatry 1999, 156(11):1796-1800.

31. Fearon P. Hotopf M: Relation between headache in childhood and physical and psychiatric symptoms in adulthood: national birth cohort study. BMJ 2001, 322(7295):1145.

32. Morris-Yates A, Talley NJ, Boyce PM, Nandurkar S, Andrews G: Evidence of a genetic contribution to functional bowel disorder. Am J Gastroenterol 1998, 93(8):1311-1317.

33. Larsson B, Bille B, Pedersen NL: Genetic influence in headaches: a Swedish twin study. Headache 1995, 35(9):513-519.

34. Kashikar-Zuck S, Lynch AM, Slater S, Graham TB, Swain NF, Noll RB: Family factors, emotional functioning, and functional impairment in juvenile fibromyalgia syndrome. Arthritis Rheum 2008, 59(10):1392-1398.

35. Groholt EK, Stigum H, Nordhagen R, Kohler L: Recurrent pain in children, socio-economic factors and accumulation in families. Eur J Epidemio 2003, 18(10):965-975.

36. Levy RL, Langer SL, Whitehead WE: Social learning contributions to the etiology and treatment of functional abdominal pain and inflammatory bowel disease in children and adults. World J Gastroenterol 2007, 13(17):2397-2403.

37. Whitehead WE, Crowell MD, Heller BR, Robinson JC, Schuster MM, Horn S: Modeling and reinforcement of the sick role during childhood predicts adult illness behavior. Psychosom Med 1994, 56(6):541-550.

38. Walker LS, Zeman JL: Parental response to child illness behavior. J Pediatr Psychol 1992, 17(1):49-71

39. Simon GE, Gureje O: Stability of somatization disorder and somatization symptoms among primary care patients. Arch Gen Psychiatry 1999, 56(1):90-95.

40. Hay EM, Dunn KM: Prognosis of low back pain in primary care. BMJ 2009, 339:b3694.

41. de Lusignan S: The barriers to clinical coding in general practice: a literature review. Med Inform Internet Med 2005, 30(2):89-97.

42. Jordan K, Clarke AM, Symmons DP, Fleming D, Porcheret M, Kadam UT, Croft P: Measuring disease prevalence: a comparison of musculoskeletal disease using four general practice consultation databases. $\mathrm{Br} J$ Gen Pract 2007, 57(534):7-14

43. Department of Health Andrew Lansley: Moving forward on modernising the NHS. 2011 [http://webarchive.nationalarchives.gov.uk/+/www.dh.gov. uk/en/MediaCentre/Pressreleases/DH_128162?PageOperation=email]

doi:10.1186/s12875-014-0195-4

Cite this article as: Shraim et al:: Repeated primary care consultations for non-specific physical symptoms in children in UK: a cohort study. BMC Family Practice 2014 15:195. 